\title{
PREY SELECTION BY THE NEOTROPICAL SPIDER ALPAIDA TUONABO WITH NOTES ON WEB-SITE TENACITY'
}

\author{
By Todd E. Shelly \\ Department of Biology \\ University of California \\ Los Angeles, CA 90024
}

\section{INTRODUCTION}

Prey selection by web-building spiders includes 2 principle components. First, webs may catch a nonrandom sample of the available prey (passive selection). Among items caught in the web, the spider may then feed on preferred prey but reject unsuitable prey (active selection). As evident from a recent review (Riechert and Luczak 1982), quantitative field measurements of either component are relatively rare and particularly so for tropical species.

Here I compare the web contents of Alpaida tuonabo (Chamberlin and Ivie) with sticky trap samples of available prey. Field work was conducted at one site over a relatively short period of time thus reducing potential complications arising from habitat and seasonal differences in prey availability. As Olive (1980) and Uetz et al. (1978) found, however, prey availability may vary over short vertical distances, and to examine this possibility potential prey were sampled at several different heights.

In addition, a second comparison was made between captured items being eaten and those left unattacked and uneaten. Since prey ignored during the day may have been consumed at night with the web, uneaten prey did not necessarily represent rejected prey. This comparison, however, does quantify the probability of immediate attack upon different types and sizes of captured prey.

IWhile Araneus is the accepted generic designation, this species is not closely related to other members of this genus and should perhaps be placed in the genus Aplaida (H. Levi pers. comm.).

Manuscript received by' the editor December 20, 1982. 


\section{Materials and Methods}

The study was conducted between July 23 and August 25, 1980, on Barro Colorado Island (BCI), Panama. This time period falls near the middle of a rainy season which annually extends from late April to mid-December (Croat 1978). The island is covered by a lowland tropical moist forest (Holdridge et al. 1971). Alpaida tuonabo was most abundant on the island's central plateau, and all work was conducted there.

Very little is known about the biology of $A$. tuonabo. A description of the female has been published (Chamberlin and Ivie 1936), but males have not yet been described ( $\mathrm{H}$. Levi, pers. comm.). Females are relatively small; the mean wet weight and body length of 8 adult females were $0.023 \mathrm{~g}(\mathrm{SD} 0.005)$ and $5.6 \mathrm{~mm}$ (SD 0.94), respectively. Females appeared to construct and tend webs during the day and consume them at night. In 4 nights of searching, I never saw a female or an intact web. On BCI $A$. tuonabo is abundant only in the mid to late wet season (July to December) and is rarely found during the rest of the year (Lubin 1978).

Flying insects were sampled at 10 different sites. At each site I implanted a $2.7 \mathrm{~m} \mathrm{PVC}$ pole (diameter $25 \mathrm{~mm}$ ) by driving $0.30 \mathrm{~m}-$ $0.45 \mathrm{~m}$ of its length into the ground. Wooden rods (length $30 \mathrm{~mm}$; diameter $5 \mathrm{~mm}$ ) were then fastened to the pole at $0.3 \mathrm{~m}$ intervals (from $0.3 \mathrm{~m}$ to $2.1 \mathrm{~m}$ above ground). Fastened at one end, each rod projected perpendicularly from the vertical pole and hence was parallel to the ground's surface. Insects were collected on tanglefoot covered traps suspended from the wooden rods. Each trap was a $15 \mathrm{~cm}$ by $23 \mathrm{~cm}$ rectangle of $3 \mathrm{~mm}$ thick transparent plastic coated on both sides with tanglefoot. Insects were sampled during the day only on August 7-9. Each day the traps were set between 0800 hrs-0900 hrs, taken down between $1600 \mathrm{hrs}-1700 \mathrm{hrs}$, and stored overnight in closed boxes. Aside from Diptera and Hymenoptera, all trapped insects were identified to order. Flies were categorized as either nematocerous or non-nematocerous, and hymenopterans were subdivided into bees and wasps, parasitoids, and winged ants. All trapped insects were measured to the nearest $0.1 \mathrm{~mm}$ using a dissecting microscope equipped with a disc micrometer.

Each day of the study I walked through different areas of the forest (between 0900-1630 hrs) and examined every web encountered. All caught items were collected and labelled as either eaten or 

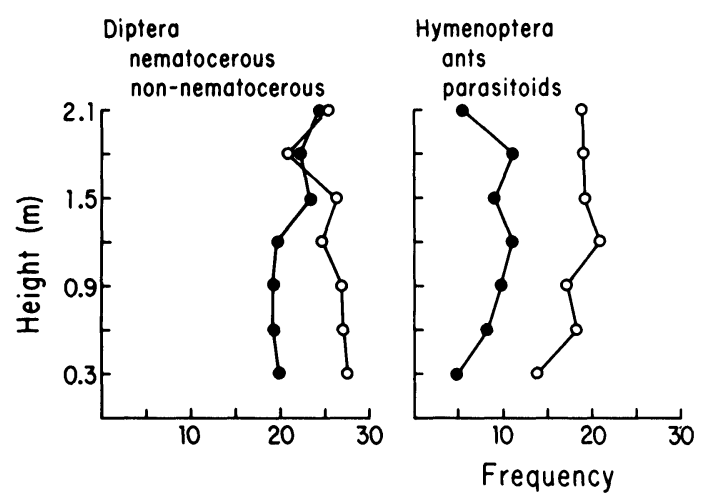

Coleoptera

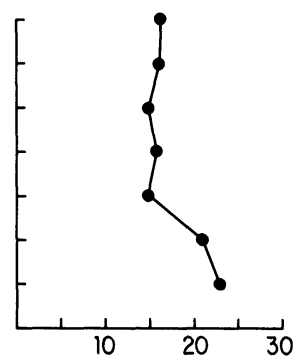

Figure 1. Vertical distributions of the major prey categories. Each value represents the total number of individuals captured on 10 sticky traps suspended at a particular height. See text for details of sampling method.

uneaten. Uneaten prey were also examined for evidence of wrapping. For each web thus sampled, the height of the spider was also recorded. Collected prey were later assigned to the appropriate prey category and measured to the nearest $0.1 \mathrm{~mm}$.

Prey selectivity was quantified using Ivlev's (1961) index of electivity. Electivity $(E)$ is calculated as follows: $E=\left(r_{i}-p_{i}\right) /\left(r_{i}+p_{i}\right)$ where $r_{i}$ is the proportion of the predator's diet represented by prey type (or size class) $i$, and $p_{i}$ is the proportion of the available prey represented by prey type (or size class) $i$. Values of $E$ range from -1.0 (complete avoidance) to +1.0 (complete preference). In this study electivity values with absolute values less than 0.40 were not considered to differ significantly from zero. In addition, two sets of electivity values were calculated. For web selectivity $\left(E_{W}\right) r_{i}$ is the proportion of the web contents (both eaten and uneaten items) represented by prey type $i$, and $p_{i}$ is the proportion of available prey (as measured by the sticky traps) represented by prey type i. For spider selectivity $\left(E_{S}\right) r_{i}$ is the proportion of the spider's observed diet (the eaten prey) represented by prey type $i$, and $p_{i}$ is the proportion of the web contents (both eaten and uneaten items) represented by prey type $\mathrm{i}$.

\section{RESULTS}

Alpaida tuonabo females generally constructed webs in relatively open sections of the forest or at the edges of tree-fall gaps. Most web 
sites were shaded, and only rarely was a web placed in an area that received direct sunlight. Various web support structures were utilized, including leaf tips, herbaceous stems, woody vines and branches, and palm fronds. The circular webs averaged $21.6 \mathrm{~cm}$ in diameter and $350 \mathrm{~cm}^{2}$ in catching area $(\mathrm{n}=8)$.

Individuals do not appear to remain at a particular web-site for more than 1-2 days. On August 3 I marked the location of 20 occupied webs. These sites were then revisited daily for 7 days, and the presence or absence of the spider and the web was recorded. In terms of the number of spiders remaining at their initial site, the results obtained were as follows: Day $1-12$; Day 2-3; Days 3 and 4-2; Days 5 and 6-1; Day 7-0. In no instance was a spider absent but the web present; spider and web were always both present or both absent. In addition, in examining a $2 \mathrm{~m}-3 \mathrm{~m}$ radius about each vacated web-site, I never observed the presence of a newly constructed web.

Five prey categories comprised $89.0 \%$ of the total sample, and vertical abundance patterns were examined for these groups only. Beetles, parasitoid Hymenoptera, nematocerous and nonnematocerous Diptera all exhibited a similar trend in vertical abundance (Figure 1). That is, the greatest numbers of individuals were collected at the two lowest sampling heights $(0.3 \mathrm{~m}$ and $0.6 \mathrm{~m})$. While similar numbers of parasitoid Hymenoptera were captured at the two lowest sampling heights, nearly twice as many beetles, nematocerous and non-nematocerous Diptera were captured at $0.3 \mathrm{~m}$ than $0.6 \mathrm{~m}$. Ants were captured in relatively constant numbers over all sampling heights.

Although the numbers of trapped individuals varied greatly with height for 4 prey categories, each major category comprised a relatively constant proportion of the total sample at each height (Figure 2). Similarly, within each category size frequency distributions did not vary with height in any obvious manner (Figure 3). Thus, while the abundance of flying insects varied with height, the taxonomic and size composition of this fauna did not.

The vertical distribution of $A$. tuonabo did not closely match that observed for available prey (Figure 4). Alpaida tuonabo preferred web-sites between $0.6 \mathrm{~m}-1.2 \mathrm{~m}$, and approximately $60 \%$ of the spiders measured were within this range. Thus, while traps nearest the ground caught the greatest numbers of flying insects, only $18 \%$ of $A$. tuonabo were found below $0.6 \mathrm{~m}$. 

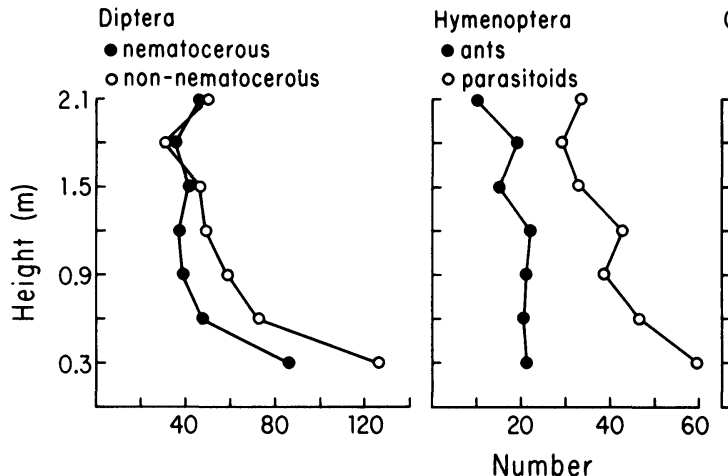

Coleoptera

nematocerous

Figure 2. Relative abundances of major prey categories over all heights sampled. Each value represents a proportion of the total number of individuals captured on 10 sticky traps suspended at a particular height. See text for details of sampling method.

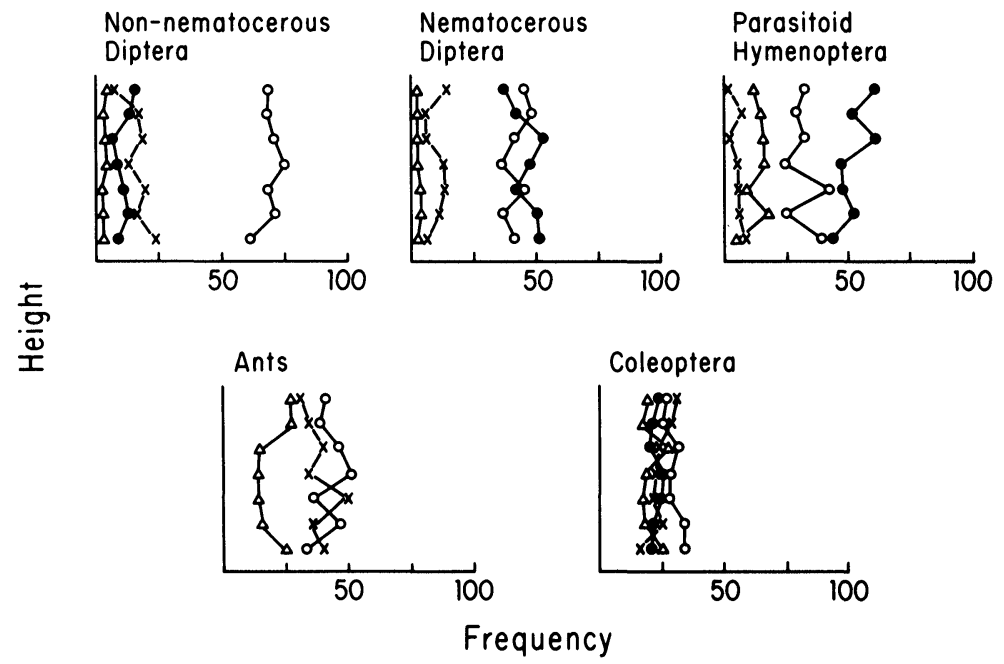

Figure 3. Size frequency distributions for the major prey categories over the 7 heights sampled. Within a category each value represents the proportion of individuals captured at a particular height that fell within a particular $1 \mathrm{~mm}$ interval. The symbols used for the various size classes are: $0-1 \mathrm{~mm}(0), 1-2 \mathrm{~mm}(0), 2-$ $3 \mathrm{~mm}(\times)$, and $>3 \mathrm{~mm}(\Delta)$. 
A total of 446 insects representing 6 orders were taken from 320 webs of A. tuonabo. Approximately $95 \%$ of these insects belonged to those 5 prey categories which were most abundant in the sticky trap samples. Consequently, analysis of both web and spider selectivities will focus only upon these groups. In addition, since the composition of the flying insect fauna did not much vary with height, both the data regarding prey availability and diet were combined over all heights.

Web selectivity values did not differ greatly from zero for beetles, nematocerous Diptera, or parasitoid Hymenoptera (Table 1). Nonnematocerous Diptera, however, comprised a small proportion of the web contents relative to their proportion on the traps. Conversely, ants represented a large proportion of the web contents relative to their proportion on the traps.

Aside from nematocerous Diptera, A. tuonabo were observed to consume prey types in proportions roughly equal to their proportion in the web (Table 2). Spider selectivity values for beetles, ants, non-nematocerous Diptera, and parasitoid Hymenoptera were all less than 0.20 (absolute value). In contrast, the $\mathrm{E}_{\mathrm{S}}$ value for nematocerous Diptera was large and negative.

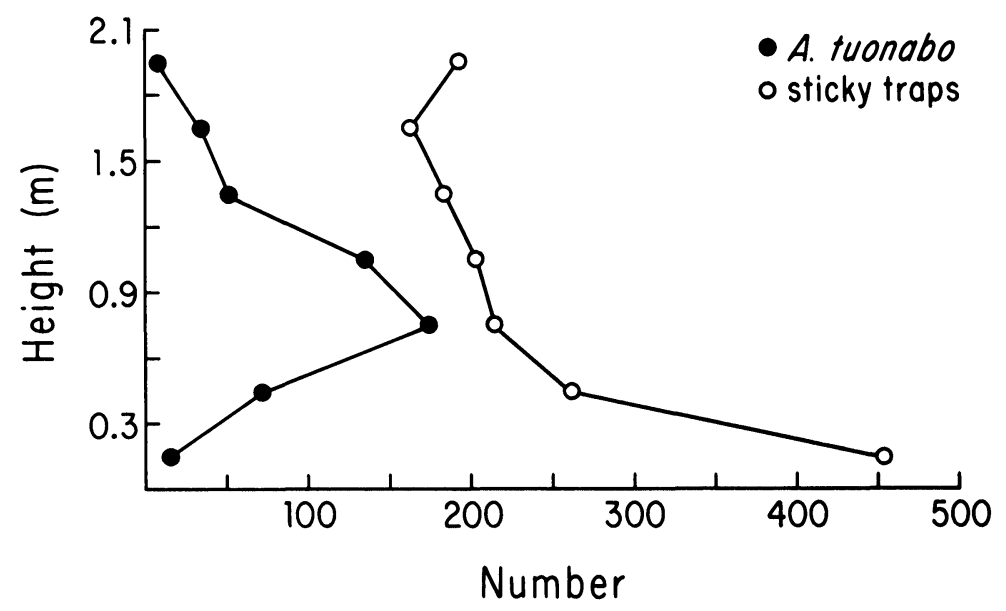

Figure 4. Vertical distribution of $A$. tuonaho and available prey. Heights of hub-resting spiders were measured to the nearest $\mathrm{cm}$ and then placed into $0.3 \mathrm{~m}$ intervals. Values for prey represent the total number of insects captured on 10 sticky traps suspended at a particular height. See text for details of sampling method. 
Table 1. Web selectivity $\left(\mathrm{E}_{\mathrm{W}}\right)$ values for prey types collected from webs of $A$. tuonabo.

\begin{tabular}{lrrrrr}
\hline Prey type & \multicolumn{3}{c}{$\begin{array}{c}\text { Collected from webs } \\
\text { (eaten and uneaten) } \\
\text { no. }\end{array}$} & \multicolumn{1}{c}{ Captured on traps } & \\
& & no. & $\mathrm{p}_{\mathbf{i}}$ & $\mathrm{E}_{\mathbf{w}}$ \\
\hline Beetles & 56 & 12.5 & 320 & 19.2 & -0.21 \\
Nematocerous Diptera & 164 & 36.8 & 337 & 20.2 & +0.29 \\
Non-nematocerous Diptera & 34 & 7.6 & 453 & 27.1 & -0.56 \\
Ants & 128 & 28.7 & 119 & 7.1 & +0.60 \\
Parasitoid Hymenoptera & 42 & 9.4 & 264 & 15.8 & -0.25 \\
Others & $22^{*}$ & 4.8 & $175^{* *}$ & 10.4 & ---- \\
\hline
\end{tabular}

*Others include: butterflies (6), bees and wasps (10), leafhoppers (4), thrips (2)

**Others include: butterflies (2), bees and wasps (2), leafhoppers (80), thrips (27), Hemiptera (8), Orthoptera (5), Collembola (3), Zoraptera (4), Plecoptera (3), Isoptera (21), Psocoptera (20)

As the $\mathrm{E}_{\mathrm{S}}$ values imply, the majority $(87 \%)$ of uneaten prey were nematocerous Diptera. Most of these, in turn, did not appear to have been wrapped. Many, in fact, were observed struggling in web while stuck by a single wing. Similarly, most uneaten nonnematocerous Diptera and parasitoid Hymenoptera were apparently unwrapped. In contrast, 9 of the 12 uneaten ants had clearly been attacked and wrapped.

Only 2 groups, nematocerous Diptera and ants, were found in webs in sufficient numbers to allow meaningful calculation of web selectivity values for different size classes. Nematocerans less than 1 $\mathrm{mm}$ were relatively more abundant in webs than on the traps, while the opposite was true for those between $1 \mathrm{~mm}-2 \mathrm{~mm}$ (Table $3 \mathrm{a}$ ). Web selectivity values, however, did not differ greatly from zero for either size class. Ants in webs were rather uniformly distributed among 8 size classes (Table $3 \mathrm{~b}$ ). The majority $(76.0 \%$ ) of ants on the sticky traps, however, were less than $3 \mathrm{~mm}$ long. Consequently, web selectivity values for the $1 \mathrm{~mm}-2 \mathrm{~mm}$ and $2 \mathrm{~mm}-3 \mathrm{~mm}$ size classes were large and negative, while those for larger classes were all large and positive.

Only ants were eaten in sufficient numbers to allow meaningful calculation of spider selectivity values for different size classes. Yet, since nearly all $(90.6 \%)$ of the ants taken from webs were being eaten, these selectivity values provide little new information. Among the remaining groups, only nematocerous Diptera had large enough 
Table 2. Spider selectivity $\left(\mathrm{E}_{\mathrm{s}}\right)$ values for prey types collected from webs of $A$. tuonabo.

\begin{tabular}{lrrrrr}
\hline Prey type & \multicolumn{3}{c}{$\begin{array}{c}\text { Collected from webs } \\
\text { (eaten only) }\end{array}$} & \multicolumn{3}{c}{ Collected from webs } \\
& no. & \multicolumn{1}{c}{$\mathrm{r}_{\mathrm{i}}$} & \multicolumn{1}{c}{ no. } & \multicolumn{1}{c}{$\mathrm{p}_{\mathrm{i}}$} & $\mathrm{E}_{\mathrm{s}}$ \\
\hline Beetles & 52 & 18.8 & 56 & 12.5 & +0.20 \\
Nematocerous Diptera & 32 & 11.6 & 164 & 36.8 & -0.52 \\
Non-nematocerous Diptera & 28 & 10.1 & 34 & 7.6 & +0.14 \\
Ants & 116 & 42.0 & 128 & 28.7 & +0.19 \\
Parasitoid Hymenoptera & 32 & 11.6 & 42 & 9.4 & +0.10 \\
Others & $16^{*}$ & 5.8 & $22^{* *}$ & 4.8 &.--- \\
\hline
\end{tabular}

*Others include: butterflies (6), bees and wasps (10)

**Others include: butterflies (6), bees and wasps (10, leafhoppers (4), thrips (2)

numbers of eaten (32) and uneaten (132) individuals to permit comparison. Mean body lengths for eaten $(x=1.6 \mathrm{~mm} ; \mathrm{SD}=1.8)$ and uneaten $(\mathrm{x}=0.8 \mathrm{~mm} ; \mathrm{SD}=0.29)$ nematocerans were significantly different $(\mathrm{t}=4.86 ; \mathrm{p}<.001)$.

\section{Discussion}

The present findings highlight 2 features of the predatory behavior of $A$. tuonabo. First, the webs captured and the spiders consumed nonrandom samples of the available prey. Nonrandom web captures have been recorded for other spiders (e.g. Uetz and Biere 1980; Brown 1981; Turnbull 1960) and most likely reflect differing abilities for web avoidance or escape among different prey. While no avoidance was observed, I did see several large flies (Asilidae and Tabanidae) strike webs but then successfully escape. Among insects successfully restrained by the web, the spider may attack, ignore, or reject different types and/or sizes of prey. Numerous studies (e.g. Robinson and Robinson 1970, 1973; Riechert and Tracy 1975; Turnbull 1960) note rejected prey, but few studies (Uetz and Biere 1980) quantify attack vs. ignore probabilities for different prey. Here, the tendency of $A$. tuonabo to ignore nematocerans probably does not reflect avoidance but rather the inability of these small, weak-flying insects to escape or damage the web. Thus, A. tuonabo may have ignored these weak prey only to consume them with their web in the evening. Interestingly, the mean body length of nematocerans being consumed was nearly twice that of nematocerans 
Table 3. Web selectivity ( $E_{W}$ values for size classes of nematocerous Diptera and ants collected from webs of $A$. tuonabo.

a. Nematocerous Diptera

\begin{tabular}{|c|c|c|c|c|c|}
\hline \multirow[t]{2}{*}{ Size $(\mathrm{mm})$} & \multicolumn{2}{|c|}{$\begin{array}{l}\text { Collected from webs } \\
\text { (eaten and uneaten) }\end{array}$} & \multicolumn{2}{|c|}{ Captured on traps } & \multirow[b]{2}{*}{$\mathrm{E}_{\mathrm{w}}$} \\
\hline & no. & $\mathrm{r}_{\mathrm{i}}$ & no. & $\mathrm{p}_{\mathrm{i}}$ & \\
\hline $0-1$ & 118 & 71.9 & 138 & 40.7 & +0.28 \\
\hline $1-2$ & 40 & 24.4 & 163 & 48.1 & -0.33 \\
\hline $2-3$ & 4 & 2.4 & 31 & 9.1 & -0.58 \\
\hline$>3$ & 2 & 1.2 & 7 & 2.1 & -0.27 \\
\hline \multicolumn{6}{|l|}{ b. Ants } \\
\hline \multirow[t]{2}{*}{ Size $(\mathrm{mm})$} & \multicolumn{2}{|c|}{$\begin{array}{l}\text { Collected from webs } \\
\text { (eaten and uneaten) }\end{array}$} & \multicolumn{2}{|c|}{ Captured on traps } & \\
\hline & no. & $\mathrm{r}_{\mathrm{i}}$ & no. & $\mathrm{p}_{\mathrm{i}}$ & $\mathrm{E}_{\mathrm{w}}$ \\
\hline$\overline{0-1}$ & 0 & 0.0 & 0 & 0.0 & $-\cdots$ \\
\hline $1-2$ & 17 & 13.3 & 43 & 36.7 & -0.47 \\
\hline $2-3$ & 11 & 8.6 & 46 & 39.3 & -0.64 \\
\hline $3-4$ & 21 & 16.4 & 7 & 6.0 & +0.46 \\
\hline $4-5$ & 16 & 12.5 & 3 & 2.6 & +0.65 \\
\hline $5-6$ & 10 & 7.8 & 3 & 2.6 & +0.50 \\
\hline $6-7$ & 24 & 18.7 & 7 & 6.0 & +0.51 \\
\hline $7-8$ & 13 & 10.2 & 2 & 1.7 & +0.71 \\
\hline$>8$ & 16 & 12.5 & 6 & 5.1 & +0.42 \\
\hline
\end{tabular}

caught in the web but ignored. Spider selectivity for larger prey has also recently been demonstrated for Micrathena gracilis (Uetz and Biere 1980).

Second, A. tuonabo did not construct their webs at heights where total prey abundance was greatest. Since the taxonomic and size composition of the flying insect fauna varied only slightly with height, $A$. tuonabo was apparently not responding to the vertical distribution of a particular type or size of prey. Several factors potentially affect web height in A. tuonabo. First, although females use various support structures, the number of suitable "web spaces" may be limited (Lubin pers. comm.). Also, other species of similar size (e.g. Pronous tuberculifer, Edricus crassicaudus, and Leucauge sp.) construct webs closer to the ground (Lubin 1978; Shelly pers. obs.). Thus, the higher webs of $A$. tuonabo may reflect a behavioral means to lessen interspecific competition for food. In addition, 
increased web height may reduce risks of predation from ground- or litter-dwelling predators.

\section{ACKNOWLEDGEMENTS}

I thank H. Levi, M. Robinson, Y. Lubin, and particularly C. Olive for helpful comments on an earlier draft. H. Levi identified the species. D. Weinberger kindly helped process the sticky trap samples. The Smithsonian Tropical Research Institute provided logistic support.

\section{Literatiri: Cited}

BROWN, K.

1981. Foraging ecology and niche partitioning in orb-weaving spiders. Oecologia 50: 380-385.

Chamberlin, R. V. and W. Ivil.

1936. New spiders from Mexico and Panama. Bull. Univ. Utah 27: 1-103.

CROAT, T. B.

1978. Flora of Barro Colorado Island. Stanford Univ. Press, Stanford.

Holdridge, L. R., W. C. Grinke, W. H. Hatheway, T. Liang, and J. A. Tosi, Jr.

1971. Forest environments in tropical life zones: a pilot study. Pergamon Press, San Francisco.

IVIev, V. S.

1961. Experimental ecology of the feeding of fishes. Yale Univ. Press, New Haven.

LIBIN, Y. D.

1978. Seasonal abundance and diversity of web-building spiders in relation to habitat structure on Barro Colorado Island, Panama. J. Arachnol. 6: $31-51$.

Olive, C. W.

1980. Foraging specializations in orb-weaving spiders. Ecology 61: 1133-1144.

Riechert, S. E. And C. R. Trac'y.

1975. Thermal balance and prey availability: bases for a model relating website characteristics to spider reproductive success. Ecology 56: 265-284.

Riechert, S. E. AND J. LII'ZAK.

1982. Spider foraging: behavioral responses to prey. In Spider communication. eds. P. N. Witt and J. S. Rovner. Princeton Univ. Press, Princeton, NJ.

ROBINSON, M. H. AND B. ROBINSON.

1970. Prey caught by a sample population of the spider Argiope argentata (Araneae: Araneidae) in Panama: a year's census data. Zool. J. Linn. Soc. 49: 345-357.

RoBinson, M. H. AND B. ROBINSON.

1973. Ecology and behavior of the giant wood spider Nephila maculata (Fabricius) in New Guinea. Smithsonian Contrib. Zool. No. 149. 
Turnblill, A. L.

1960. The prey of the spider Lin!phia triangularis (Clerck) (Araneae, Linyphiidae). Can. J. Zool. 38: 859-873.

Untz, G. W., A. D. Johnson, and D. W. S( hemske.

1978. Web placement, web structure, and prey capture in orb-weaving spiders. Bull. Br. Arachnol. Soc. 4: 141-148.

Uetz, G. W. AND J. M. Biere.

1980. Prey of Micrathena gracilis (Walckenaer) (Araneae: Araneidae) in comparison with artificial webs and other trapping devices. Bull. Br. Arachnol. Soc. 5: 101-107. 

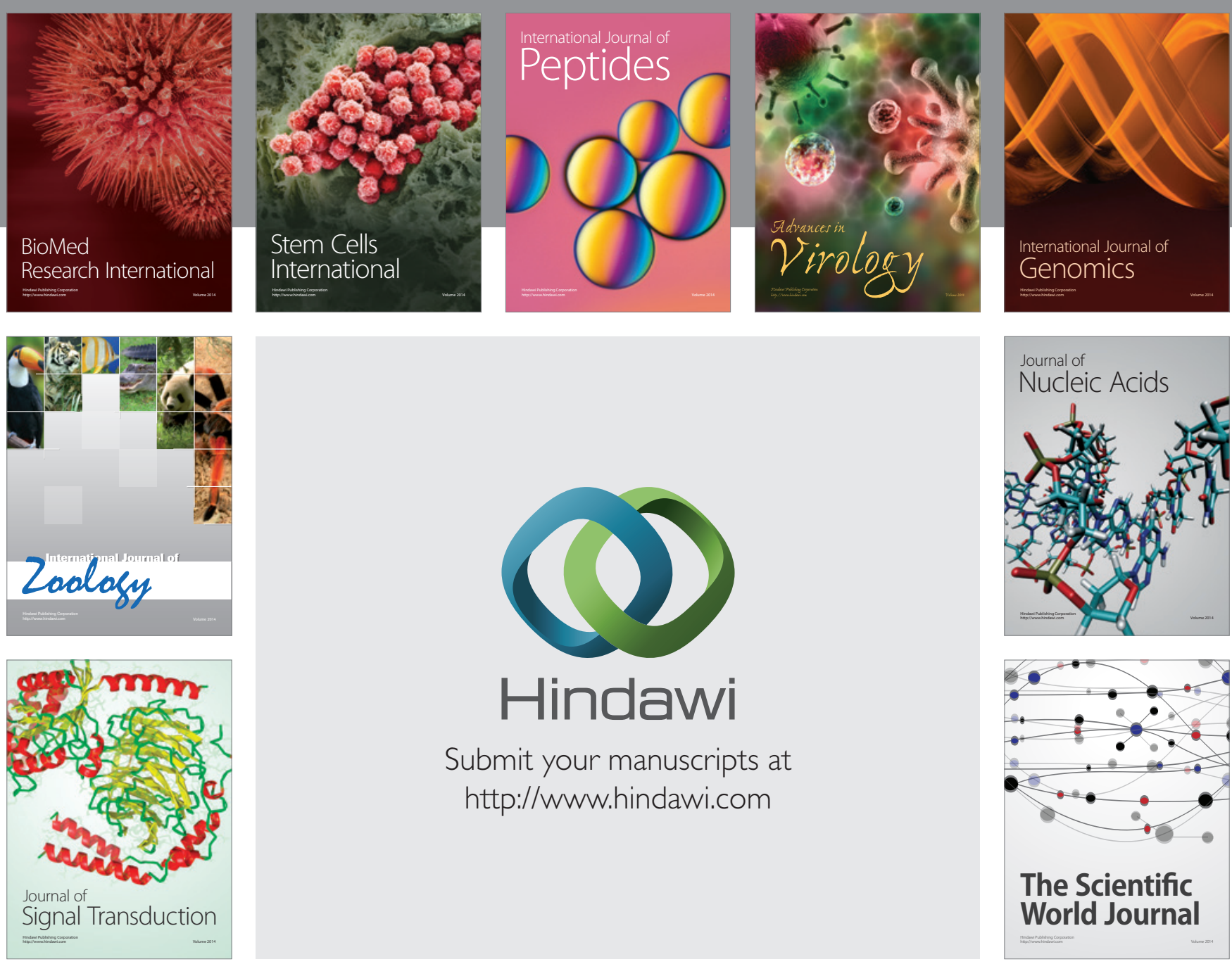

Submit your manuscripts at

http://www.hindawi.com
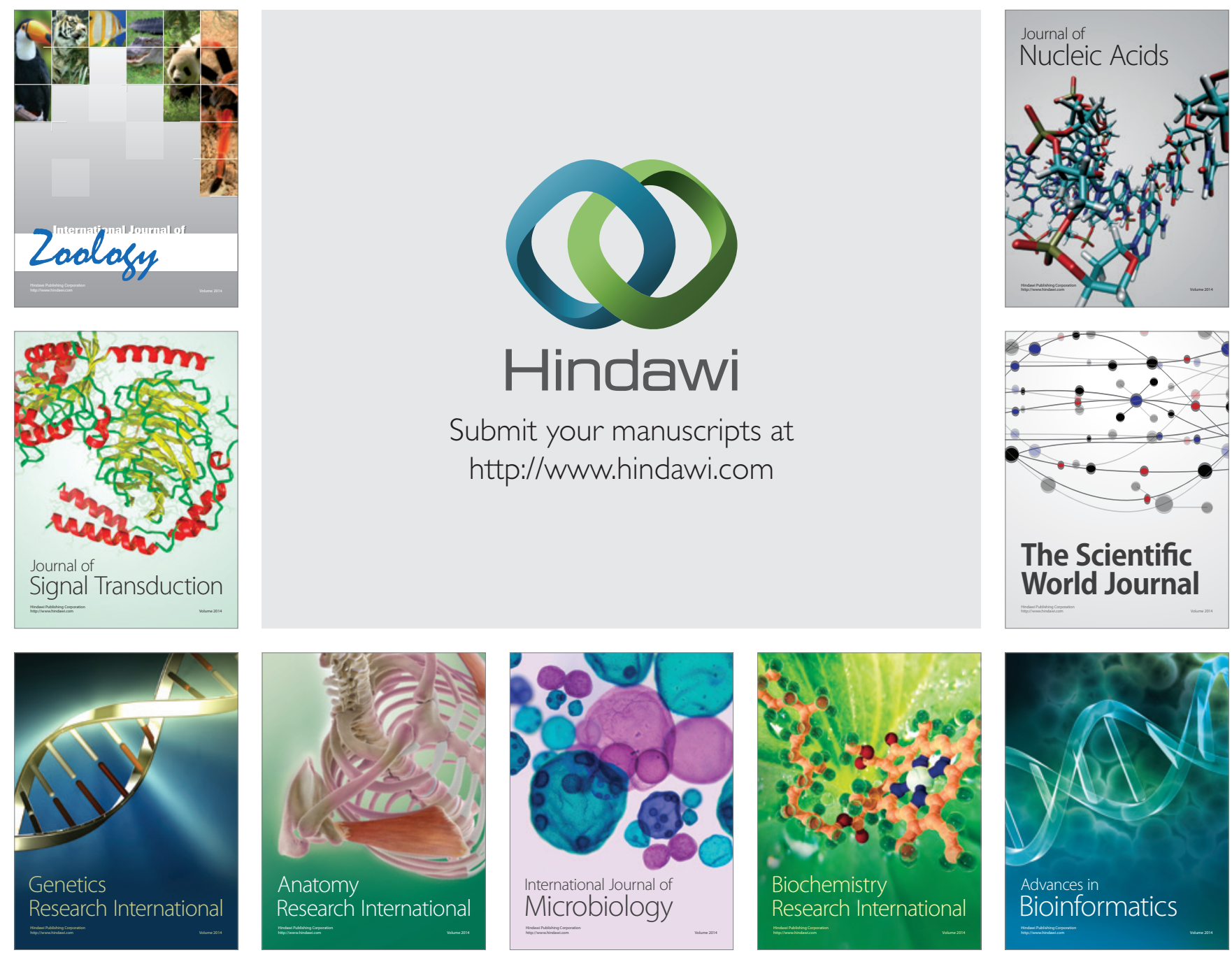

The Scientific World Journal
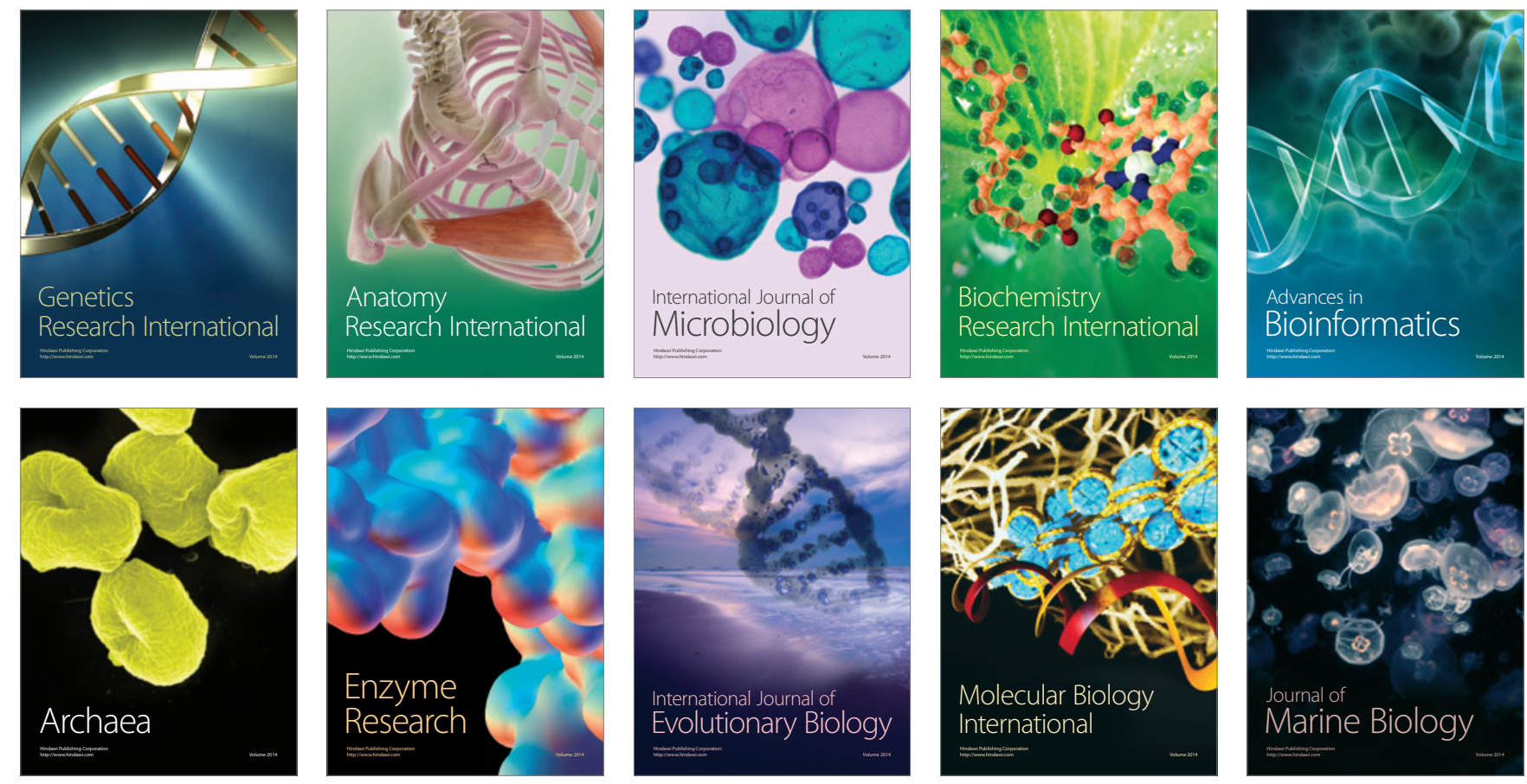